\title{
The Doctrine of Reality: A New Paradigm of Science
}

\author{
Temur Z. Kalanov \\ Home of Physical Problems, Yozuvchilar (Pisatelskaya) 6a, 100128 Tashkent, Uzbekistan
}

\begin{abstract}
The doctrine of reality and a new paradigm of science are proposed. The unity of formal logic and rational dialectics is the correct methodological basis for the solution of the problem of reality. The main result is the following system of conceptions: (1) reality represents the unity of opposites: the controlling (governing) aspect and the controllable aspect. The controlling (governing) aspect is God, and the controllable aspect is the Universe; (2) the principle of existence and of uniqueness of God reads as follows: the scientific object "Absolute, Creator, and Governor of essence (information) and of material manifestation of essence" exists. This scientific object is the unique and correct theoretical model (identifier) of the religious object "God (Creator and Governor of the World)"; (3) the Universe represents the informational-material system: the unity of essence (information) and of material manifestation of essence. The manifestation of information is matter. The material structure of the Universe represents the set of states of matter: the physical vacuum, the system block, the ether, and the discrete objects; (4) God created the system block, the ether and the objects, entering information into the physical vacuum. God governs the Universe by means of information; (5) the correct science of the 21 st century should research the fundamental relation between the controlling (governing) information and the material manifestation of the controlling (governing) information in the Universe.
\end{abstract}

Keywords: physics; biophysics; astrophysics, cosmology; UFO science; parapsychology; metaphysics; formal logic; dialectics; philosophy.

\section{(4) (1) CC BY: Creative Commons Attribution License 4.0}

\section{Introduction}

As is known, the achievements of science in the 20th century seemed so significant that scientists did not question the foundations of science within the framework of the correct methodological basis: the unity of formal logic and rational dialectics. The correct methodological basis is a criterion of truth. In the 21 st century, the fact becomes obvious that many problems of science cannot be understood and solved outside the framework of the correct methodological basis. [1-121], it was first shown within the framework of the correct methodological basis that the foundations of theoretical physics, mathematics, and materialistic dialectics (dialectical materialism) contain formal-logical errors. In other words, the foundations of the sciences do not satisfy the criterion of truth. The elimination (removal) of the errors leads to the abolition of standard theories. This implies that science enters into the greatest crisis. This fact proves that the standard paradigm of science must be revised and replaced by the correct paradigm. A correct paradigm of science can be formulated only within the framework of the correct methodological basis (i.e., the criterion of truth). The methodological basis determines the paradigm; paradigm characterizes the methodological basis. Human knowledge represents an expression of reality within the framework of the methodological basis (paradigm).

The purpose of this work is to propose a new, correct paradigm of science within the framework of the correct methodological basis: the unity of formal logic and rational dialectics.

\section{The Unity of Formal Logic and Rational Dialectics as a Doctrine of Reality}

The unity of formal logic and rational dialectics represents the correct doctrine of reality, the correct criterion of truth and, therefore, the framework of the correct paradigm of science. The foundations of the correct doctrine of reality are as follows [1-121].

1. The rational dialectics is the corrected materialistic dialectics (dialectical materialism). The rational dialectics contains the following main laws of existence [11-15, 26, 66, 69, 75, 76, 85-87, 89, 94]: the law of eternal existence and the uniqueness of God as the scientific object "Absolute, Creator, and Governor of essence (information) and of material manifestation of essence"; God is an aspect of reality; the law of the eternal existence of matter and information; the law of the existence of the relation (interconnection, interdependence) of matter and information; the law of existence of set of states of matter and information.

These laws should be supplemented with three known laws of materialistic dialectics: the law of the unity and struggle of opposites (i.e., the law of the unity of stability and changeability); the law of transition of quantitative changes into qualitative changes (i.e., the law of the existence of a measure); the law of negation of negation (i.e., the law of direction of change). Also, paired categories as methodological principles of materialistic dialectics should be used: for example, the essence and phenomenon; content and form; birth and extermination.

2. The main epistemological principle of rational dialectics is the principle of existence. The principle of existence expresses the principle of logical completeness: (a) if "World (Universe)" exists, then "Non-World (Non- 
Universe)" exists; if "Non-World (Non-Universe)" exists, then "World (Universe)" exists; (b) "Non-World (NonUniverse)" is God. The principle of existence and of uniqueness of God reads as follows: the scientific object "Absolute, Creator, and Governor of essence (information) and of manifestation of essence (phenomenon)" exists. This scientific object is the unique and correct theoretical model (identifier) of the religious object "God (Creator and Governor of the World)"; (c) if "Matter" exists, then "Non-Matter" exists; if "Non-Matter" exists, then "Matter" exists. "Non-Matter" is not emptiness. "Non-Matter" is information; (d) if "Matter that has properties (information)" exists, then "Matter that has no properties (information)" exists; if "Matter that has no properties (information)" exists, then "Matter that has properties (information) exists; (e) if "Discrete state of matter (a set of discrete objects)" exists, then "Non-discrete state of matter (i.e., a field)" exists; if "Non-discrete state of matter (i.e., a field)" exists, then "Discrete state of matter (i.e., a set of discrete objects)" exists.

The principle of non-existence (absence) of emptiness results from this. The principle of non-existence (absence) of emptiness reads as follows: emptiness as the absence of matter does not exist. The proof is as follows. One should make the following inverse assumption: if matter exists, then emptiness (as absence, non-existence of matter) exists. In this case, the following contradiction arises: if matter exists, then matter does not exist. Therefore, the assumption made is erroneous. The correct relation between concepts of matter and emptiness represents the relation of disagreement: concepts of matter and emptiness are contradictory concepts. There exists either matter or emptiness. This means that emptiness as the absence of matter in the Universe does not exist, and the bound of matter does not exist.

3. There is no general form of the formal-logical definition of matter. A proof of this assertion is as follows. According to formal logic, a concept is defined in general form via indication of the proximal (nearest) genus and the species difference (specific difference). Logic determines the following method of definition, which does it possible to indicate the essential features (signs) of the definable objects. The definable concept is led (brought) under the other, more general, concept. Moreover, the definable concept is subordinated to a more general concept. The volume (scope) of the definable concept is part of the volume (scope) of the more general concept. Thereafter, the feature (sign) which expresses the difference of the definable concept from other concepts is indicated. The volumes (scopes) of the other concepts which are also subordinated to this general concept enter into the volume (scope) of this general concept. Such method of definition is called definition by means of indication of the proximal (nearest) genus and the species difference (specific difference) (in Latin: "definitio per genus proximum et differentiam specificum"). This implies the following assertion. If one wants to define an object, one must, first of all, find the proximal (nearest) genus (in Latin: "genus proximum”), i.e. directly a wider class of objects into which the objects under consideration enter as a species. Then one must find a species difference (specific difference) (in Latin: "differentia specifica"), i.e. that feature (sign) which distinguishes (differentiates) the objects under consideration from objects of other species of the same class (genus). Thus, the definition by means of indication of the proximal (nearest) genus and species difference (specific difference) implies that all features (signs) of the definable object are not enumerated (listed), but only two features (signs) are indicated: the generic (the proximal (nearest) genus) and species features (signs).

But the highest genus cannot be defined by means of the proximal (nearest) genus and species difference (specific difference) because the higher genus for the highest genus does not exist. The concept (category) of matter represents the highest genus. Consequently, the general form of the formal-logical definition of the concept of matter does not exist.

The concept (category) of matter would be a meaningless concept if there were no genetic definition of matter.

4. The genetic definition in formal logic is a special form of definition that shows how a given object, a given phenomenon arises. The genetic definition of the concept (category) of matter is as follows: matter is the manifestation of the essence (information). The genetic definition of the concept (category) of matter would be a meaningless definition if the concept (category) of the World (Universe) did not exist.

5. From the formal-logical point of view, the concept of the World (Universe) is a single and concrete (specific) concept. The concept of the World (Universe) can be defined as follows: the World (Universe) is the unity of essence and phenomenon (i.e., manifestations of essence) where essence is information, and manifestation of essence is matter. Consequently, the concepts of World (Universe) and matter are not identical concepts.

6. The World (Universe) represents a set of states of information-matter. The World (Universe) is "reality mentally-divisible into aspects" [63, 66, 69, 75]. In other words, the World (Universe) is the system that has a structure. (Structure is a set of the stable connections between the elements in the system. These connections ensure the integrity of the system and identity to oneself, i.e., conservation of the basic properties under various changes).

God is the "reality mentally-indivisible into aspects" [63, 66, 69, 75]. Reality is defined as follows [63, 66, 69, 75]:

$$
V_{\text {(reality) }}=V_{\text {(reality divisibleinto aspects) }}+V_{\text {(reality indivisibe into aspects) }}
$$

where $V$ is the scope (volume) of the concept.

7. The material structure of the Universe represents a set of states of matter $[26,29,63,66,69,75,76,85,89]$. These states are not mutually exclusive states, but are mutually complementary (supplemental), mutually connected, mutually dependent, mutually necessary states. The states are as follows.

a) The state "physical vacuum" is the zero state of matter, containing zero information. Therefore, matter in the zero state has no properties. Matter that does not contain information is matter at rest (i.e., matter without movement) because information is the cause, the source of movement. (Movement is change in general). 
b) The state "system block" is the state of matter (organ) which collects, stores, keeps, processes, transmits information and performs informational commands of God. God controls (governs) the system block. The system block controls the Universe by means of information. (The Universe is an informational-material system. Therefore, the informational-material elements of this system are the informational-materially connected elements). The "system block" contains all the information about the past, present and future of the Universe. The "system block" has an informational impact on the Universe. Informational impact is manifested in the material form. (The informational impact can materialize (i.e., reproduce in a material form) the events of the past, present and future time).

c) The state "ether" is a state that has a single (unique) property: continuity. Continuity as the single (unique) property of matter is a nonphysical (i.e., mathematical) property of matter. "Ether" is a material field in general. The material field in general represents a non-physical field. In other words, the material field in general has no physical properties at all (for example, gravitational property, energy property). The only property of this non-physical field is mathematical continuity. Therefore, the "ether" is the passive and immovable state.

d) The state "objects" is a set of discrete informational-material objects (electrons, protons, atoms, molecules, people, planets, galaxies, etc.). The objects have physical and other properties due to information. Therefore, the objects are active and changing (i.e., moving) objects. In other words, the "object state" of matter is a set of discrete informational-material objects (micro-objects and macro-objects, including biological (stable and unstable) and nonbiological (stable and unstable) objects (for example, UFO).

8. The informational-material objects are a material manifestation of the essence (information). Each object has the measure: the unity of qualitative and quantitative determinacy. The movement of an object is a material manifestation of information. (The movement of an object is change in general). Therefore, the energy of the informational-material object is a form of manifestation of the movement of the informational-material object. Information determines movement (energy); movement (energy) characterizes information. In other words, energy is a measure of the movement of an information-material object.

An important example is the collision of two elementary particles in a collider. Any elementary particle is an informational-material object. The act of collision of two informational-material particles leads to a qualitative change (transformation) of informational-material particles: two particles turn into many other informationalmaterial particles. Each specific energy region of the colliding particles corresponds to a certain set of nascent (generated) particles. But this does not mean that the colliding particles are composed of a set of nascent (generated) particles. The set of nascent (generated) particles characterizes the act of annihilating (exterminating) the colliding particles; the act of annihilating (exterminating) the colliding particles determines the set of particles being born. In other words, a change in information leads to the birth and extermination of informational-material particles.

9. Discrete informational-material objects affect informationally on the ether (non-physical field), generating local informational-material (physical, biological, etc.) fields (for example, gravitational, electric, magnetic fields) in the ether. These local informational-material fields in the ether are associated with generating objects. Local informational-material fields are moved in immovable (fixed) ether. The local informational-material field "looks like an object's shadow, a reflection of an object in the ether, an ethereal image of an object".

10. Man (as a discrete informational-material (psychophysical) object) can generate mentally (i.e., by introducing information (thoughts) into the ether) a field phantom (ghost): an unstable informational-material object. (The process of thinking is one of the many forms of human movement as movement of informational-material object).

11. There exist local field creatures, beings (for example, angels, and devils) and local field effects (for example: telepathy, telekinesis, levitation, teleportation). The existence the local field beings and the local field effects can be detected by man if the consciousness of man is in certain state. (The consciousness of man can be in various (different) sates). For example, self-ignition of man (i.e., ignition of physiological body, not clothes) is that the psychical body of man obliterates (destroys) its physiological body by introducing information (thought) into the ether. (In other words, the psychical body burns one's physiological body, leaving the man's clothes in inalterable condition).

12. Informational-material objects (for example, UFO as "Luminous Ball") are characterized by form and content. "Luminous Ball" (as the content of the informational-material, rational, intelligent, intellectual, thinking object), interacting informationally with "informational-material Matrix", can consciously take the form (shape) of the "informational-material Matrix". In other words, "Luminous Ball", consciously reaching the region of the matrix "Birth (nativity) of Form", can consciously take the form of another informational-material object. If this object reaches the region of the matrix "Extermination (destruction) of Form", then the object turns into the "Luminous Ball". For example, if the "Luminous Ball" reaches consciously the region of the image of the bird at the Nazca Valley, the "Luminous Ball" turns into the living bird. And this living bird, consciously reaching the region of Stonehenge, loses the form (shape) of a bird and turns into "Luminous Ball". (Analogy: Sperm, reaching the region of the uterus (like a matrix), turns into a man). In addition, the "Luminous Ball" can take the form of a man, an angel, a devil, a rational, intelligent, intellectual, thinking airplane or spacecraft, etc.. Also, all known pyramids (for example, the pyramid of Cheops) - as informational-material objects - were constructed by means of informational control. The pictograms on the wheat fields are constructed by means of informational control.

Thus, all anomalous (in the point of view of man) objects and phenomena are material manifestations of controlling (governing) information. 


\section{The Correct Paradigm of Science}

1. Reality as a scientific truth is an expression of human knowledge of the Universe within the framework of the correct methodological basis: the unity of formal logic and rational dialectics.

2. The criterion of truth represents the unity of formal logic and rational dialectics.

3. The goal of science is the search, comprehension, ascertainment, fixing and development of truth. The solution of the epistemological problem of the relation between absolute and relative truth is as follows. The existence of relative truths is a consequence of the existence of absolute truth. Absolute truth is not the sum of relative truths. Absolute truth determines relative truths; relative truths characterize absolute truth.

4. Rational dialectic is the corrected materialistic dialectics (dialectical materialism). The basic idea of the rational dialectics is as follows: Creator, Governor of the Universe is God. The existence and uniqueness of God is the Absolute Truth. The principle of existence and of uniqueness of God reads as follows: there exists the scientific object "Absolute, Creator, Governor of information and of material manifestation of information". The scientific object "God" represents the unique and correct theoretical model (identifier) of the religious object "God (Creator, Governor of the World)".

5. God created the system block, the ether and the objects, introducing information into the physical vacuum. God governs the Universe by means of information. This statement shows the existence an analogy with the functioning of the "man-computer" system: a computer is the Universe; the blank screen of the computer monitor is a field in general; the objects on the screen are objects in the object state of matter; a programmer and an operator (like God) control (govern) objects by means of the system block (unit); objects do not know about the existence of a programmer and an operator.

The destination (purpose) of the science of the 21st century is to research the fundamental relation between governing (controlling) information and the material manifestation of governing (controlling) information in the Universe.

\section{Discussion}

1. As is known, the problem of building a scientific picture of the world was actively discussed by scientists in the 20th century. In the 21st century, scientists probably already understand that neither physical, nor mathematical, nor chemical, nor biological, nor any other special-scientific picture of the world can be built because: (a) all special sciences contain formal-logical and dialectical errors. In other words, the existing special sciences do not satisfy the correct criterion of truth; (b) the set of special sciences is not a system (i.e., is not unified science of the world (Universe)). Consequently, unified scientific picture of the world cannot be created. This fact means that the standard paradigm of science enters the greatest crisis.

2. Human knowledge is a consequence of the paradigm (i.e., the methodological basis of science, the criterion of truth). By definition, the paradigm is the initial conceptual scheme, the model of problem statement and of solution of problems, the set of research methods used by the scientific community during a certain historical period. The conception is a way of understanding, the interpretation of any phenomena, the main point of view, the guiding idea, the constructive principle of various activities.

As is known, the starting point and the basis of the standard paradigm of science is the statement that: (a) God does not exist, (b) Humanity is the highest stage (step) in the development of Nature. Therefore, the world can be cognized by Humanity; (c) the solution of the epistemological problem of the relation between absolute truth and relative truth is as follows: absolute truth is the sum of relative truths; the Human tendency to comprehension of absolute truth is an infinite (endless) process; (d) the inductive method (way) of cognition leads to the attainment of absolute truth; (e) the "whole" can be divided into "parts"; the cognition of the "part" leads to the cognition of the "whole". But the standard paradigm does not contain a formal-logical criterion of truth. Recently, it has become obvious that many phenomena in the world cannot be researched (cognized) within the framework of the standard paradigm. This proves the fallacy of the standard paradigm which is not a consequence of the correct methodological basis. In other words, the standard paradigm does not meet the criterion of truth.

3. The theory of systems (systems approach, systems analysis as a concretization of the laws of dialectics) reads as follows: the properties of the system of the elements determine the properties of the elements of the system; the properties of the elements of the system characterize the properties of the system of the elements. In this point of view, the research of the elements of the system "Universe" cannot lead to the cognition of the system "Universe"; cognition of the Universe as a "whole" can lead to the research of the elements as "parts".

\section{Important Examples}

The study of collisions of elementary particles in a collider cannot provide information about the structure of elementary particles because the result of a collision characterizes only the informational-material act of the qualitative change of the colliding particles. In other words, elementary particles born as a result of a collision are a material manifestation of a change in information. Elementary particles (in the exact meaning of this term) are not constituent elements ("tiny bricks") of matter. Therefore, scientists who are looking for elementary particles as constituent elements (i.e., "tiny bricks") of matter are dreamers (fumblers).

The dreamers (fumblers) in science existed at all times. The great dreamers (fumblers) of the 19th and 20th centuries created, for example, statistical physics, the special theory of relativity, the general theory of relativity, quantum mechanics, and quantum electrodynamics, the theory of "Big Bang". The dreamers (fumblers) of the 21st century are trying to create a unified field theory. But the theories proposed by the dreamers (fumblers) do not satisfy 
the correct criterion of truth. The dreamers cannot think, analyze and create theories within the framework of the correct methodological basis. They can mislead the scientific community. Therefore, science enters into the greatest crisis.

5. The system "Universe" (as a "whole") cannot be cognized in parts (piecemeal). The system "Universe" (as a "whole") cannot be cognized in the analytical, inductive way (i.e., in the way "from particular to general"). The system "Universe" (as a "whole") can only be cognized in a meditative (non-analytical) way. The meditative method of cognition leads to the recognition of the existence of God. Recognizing the existence of God leads to a deductive approach to researching the Universe. A deductive approach to researching the Universe is possible if scientists acknowledge the existence of God as the scientific object "Absolute, Creator, Governor of essence (information) and of material manifestation of essence". In this case, the existence of God would mean and explain the limitless multiformity of aspects of the Universe, the limitless variety of life forms (organic and inorganic forms), the limitless variety of mind forms, the existence of Higher (Superior) Intellect (Intelligence), the boundedness (finiteness) of the Human Mind and the boundedness (finiteness) of science. The scientific recognition of the existence of God would be the greatest achievement of the Human Mind: the establishment (ascertainment) of the Absolute Scientific Truth. The recognition of the existence of the Absolute Scientific Truth is the starting point and the basis of the correct paradigm of science.

Thus, the goal of the correct science of the 21 st century is to research the fundamental relation between controlling information and the material manifestation of controlling information in the Universe.

\section{Conclusion}

Thus, the critical analysis of the foundations of modern science shows that: (a) science enters into the greatest crisis because science contains gross methodological errors; (b) scientific researches are not carried out within the framework of the correct methodological basis: the unity of formal logic and rational dialectics. This means that the standard paradigm of science should be replaced by the correct paradigm. The proposed science paradigm as the content of the correct methodological basis represents the following conceptual system:

1. Reality is the unity of opposites: the controlling (governing) aspect and the controllable aspect. The controlling (governing) aspect is God, and the controllable aspect is the Universe.

2. The principle of existence and of uniqueness of God reads as follows: the scientific object "Absolute, Creator, Governor of essence (information) and of material manifestation of essence" exists. This scientific object is the unique and correct theoretical model (identifier) of the religious object "God (Creator, Governor of the World)".

3. The Universe represents the informational-material system: the unity of essence (information) and of material manifestation of essence. The manifestation of information is matter. The material structure of the Universe represents the set of states of matter: the physical vacuum, the system block, the ether, and the discrete objects.

4. God created the system block, the ether and the objects, entering information into the physical vacuum. God governs the Universe by means of information.

5. The correct science of the 21 st century should research the fundamental relation between the controlling (governing) information and the material manifestation of the controlling (governing) information in the Universe.

\section{References}

[1] Kalanov, T. Z., 2018. "The formal-logical analysis of the foundation of set theory." Scientific Review, vol. 4, pp. 53-63.

[2] Kalanov, T. Z., 2018. "On new foundations of theory of atom." International Journal of Advanced Research in Physical Science, vol. 5, pp. 1-9.

[3] Kalanov, T. Z., 2018. "On the correct formulation of the starting point of classical mechanics." Physics and Astronomy International Journal, vol. 2, pp. 79-92.

[4] Kalanov, T. Z., 2017. "The formal-logical analysis of the foundation of set theory." Bulletin of Pure and Applied Sciences, vol. 36E, pp. 329 -343.

[5] Kalanov, T. Z., 2017. "On the correct formulation of the starting point of classical mechanics." International Educational Scientific Research Journal, vol. 3, pp. 56-73.

[6] Kalanov, T. Z., 2017. "On the correct formulation of the starting point of classical mechanics." International Journal of Advanced Research in Physical Science, vol. 4, pp. 1-22.

[7] Kalanov, T. Z., 2017. "On the correct formulation of the starting point of classical mechanics." Advances in Physics Theories and Applications, vol. 64, pp. 27-46.

[8] Kalanov, T. Z., 2017. "On the correct formulation of the starting point of classical mechanics." International Journal of Chemistry, Mathematics and Physics, vol. 1, pp. 27-47. Available: www.aipublications.com

[9] Kalanov, T. Z., 2017. "On the formal-logical analysis of the foundations of mathematics applied to problems in physics." Asian Journal of Fuzzy and Applied Mathematics, vol. 5, pp. 48-49.

[10] Kalanov, T. Z., 2017. "On the correct formulation of the law of the external photoelectric effect." Bulletin of the Amer. Phys. Soc.,

[11] Kalanov, T. Z., 2017. "Man versus Computer, Difference of the essences, The problem of the scientific creation." BRAIN: Broad Research in Artificial Intelligence and Neuroscience, vol. 8, pp. 151-178.

[12] Kalanov, T. Z., 2016. "Man vs. Computer, Difference of the essences. The problem of the scientific creation." International Journal of Multidisciplinary Education and Research, vol. 1, pp. 15-31. 
[13] Kalanov, T. Z., 2016. "Man vs. Computer, Difference of the essences. The problem of the scientific creation." International Journal of Contemporary Research and Review, vol. 7, Available: http://ijcrr.in/index.php/ijcrr

[14] Kalanov, T. Z., 2016. "Man vs. Computer, Difference of the essences, The problem of the scientific creation." International Journal of Scientific Research in Computer Science, Engineering and Information Technology, vol. 1, pp. 120-143.

[15] Kalanov, T. Z., 2016. "Man vs. Computer, Difference of the essences. The problem of the scientific creation." Journal of Review in Sciences, Scientific Research Gate, vol. 1, pp. 10-34.

[16] Kalanov, T. Z., 2016. "On the correct formulation of the law of the external photoelectric effect." International Journal of Informative \& Futuristic Research, vol. 4, pp. 4801-4811.

[17] Kalanov, T. Z., 2016. "On the correct formulation of the law of the external photoelectric effect." Journal of Review in Sciences, Scientific Research Gate, vol. 1, pp. 1-9.

[18] Kalanov, T. Z., 2016. "Critical analysis of the foundations of pure Mathematics." Philosophy of Mathematics Education Journal,

[19] Kalanov, T. Z., 2016. "Critical analysis of the foundations of pure mathematics." Aryabhatta Journal of Mathematics \& Informatics, vol. 8, pp. 1-14.

[20] Kalanov, T. Z., 2016. "Critical analysis of the foundations of pure mathematics." International Journal for Research in Mathematics and Mathematical Sciences, vol. 2, pp. 15-33.

[21] Kalanov, T. Z., 2016. "Critical analysis of the foundations of pure mathematics." Mathematics and Statistics, vol. 2, pp. 2-14. Available: http://crescopublications.org

[22] Kalanov, T. Z., 2016. "On the formal-logical analysis of the foundations of mathematics applied to problems in physics." Bulletin of the Amer. Phys. Soc.,

[23] Kalanov, T. Z., 2015. "On the formal-logical analysis of the foundations of mathematics applied to problems in physics." Aryabhatta Journal of Mathematics \& Informatics, vol. 7, pp. 1-2.

[24] Kalanov, T. Z., 2015. "Critical analysis of the foundations of the theory of negative numbers." Aryabhatta Journal of Mathematics \& Informatics, vol. 7, pp. 3-12.

[25] Kalanov, T. Z., 2015. "Critical analysis of the foundations of the theory of negative numbers." International Journal of Current Research in Science and Technology, vol. 1, pp. 1-12.

[26] Kalanov, T. Z., 2015. "Where are the logical errors in the theory of Big Bang?" Bulletin of the Amer. Phys. Soc., vol. 60,

[27] Kalanov, T. Z., 2015. "Critical analysis of the mathematical formalism of theoretical physics. V. Foundations of the theory of negative numbers." Bulletin of the Amer. Phys. Soc., vol. 60,

[28] Kalanov, T. Z., 2015. "Critical analysis of the mathematical formalism of theoretical physics. IV. Foundations of trigonometry." Bulletin of the Amer. Phys. Soc., vol. 60,

[29] Kalanov, T. Z., 2014. "Where are the logical errors in the theory of Big Bang?" Scientific GOD Journal, vol. 5, pp. 432-433.

[30] Kalanov, T. Z., 2014. "Critical analysis of the foundations of the theory of negative number." International Journal of Informative \& Futuristic Research, vol. 2, pp. 1132-1143. Available: www.ijifr.com

[31] Kalanov, T. Z., 2014. "On the system analysis of the foundations of trigonometry." Bulletin of Pure and Applied Sciences, vol. 33E, pp. 1-27.

[32] Kalanov, T. Z., 2014. "On the system analysis of the foundations of trigonometry." Pure and Applied Mathematics Journal, vol. 3, pp. 26-39.

[33] Kalanov, T. Z., 2014. "On the system analysis of the foundations of trigonometry." International Journal of Science Inventions Today, vol. 3, pp. 119-147. Available: www.ijsit.com

[34] Kalanov, T. Z., 2014. "On the system analysis of the foundations of trigonometry." International Journal of Informative \& Futuristic Research, vol. 1, pp. 6-27. Available: www.ijifr.com

[35] Kalanov, T. Z., 2014. "On the system analysis of the foundations of trigonometry." Journal of Physics \& Astronomy, vol. 3, Available: www.mehtapress.com

[36] Kalanov, T. Z., 2014. "Critical analysis of the mathematical formalism of theoretical physics. III. Pythagorean theorem." Bulletin of the Amer. Phys. Soc., vol. 59,

[37] Kalanov, T. Z., 2014. "Critical analysis of the mathematical formalism of theoretical physics. II. Foundations of vector calculus." Bulletin of the Amer. Phys. Soc., vol. 59,

[38] Kalanov, T. Z., 2013. "Critical analysis of the mathematical formalism of theoretical physics. II. Foundations of vector calculus." Bulletin of Pure and Applied Sciences, vol. 32 E, pp. 121-130.

[39] Kalanov, T. Z., 2013. "Critical analysis of the mathematical formalism of theoretical physics. II. Foundations of vector calculus." Unique Journal of Engineering and Advanced Sciences, vol. 1, Available: www.ujconline.net

[40] Kalanov, T. Z., 2013. "On the logical analysis of the foundations of vector calculus." Aryabhatta Journal of Mathematics \& Informatics, vol. 5, pp. 227-234.

[41] Kalanov, T. Z., 2013. "The foundations of vector calculus, The logical error in mathematics and theoretical physics." Unique Journal of Educational Research, vol. 1, pp. 054-059.

[42] Kalanov, T. Z., 2013. "On the logical analysis of the foundations of vector calculus." Research Desk, vol. 2, pp. 249-259.

[43] Kalanov, T. Z., 2013. "The critical analysis of the Pythagorean theorem and of the problem of irrational numbers." Global Journal of Advanced Research on Classical and Modern Geometries, vol. 2, pp. 59-68. 
[44] Kalanov, T. Z., 2013. "On the logical analysis of the foundations of vector calculus." Journal of Research in Electrical and Electronics Engineering, ISTP-JREEE, vol. 2, pp. 1-5.

[45] Kalanov, T. Z., 2013. "On the logical analysis of the foundations of vector calculus." Journal of Computer and Mathematical Sciences, vol. 4, pp. 202-321.

[46] Kalanov, T. Z., 2013. "On the logical analysis of the foundations of vector calculus." International Journal of Multidisciplinary Academic Research, vol. 1,

[47] Kalanov, T. Z., 2013. "On the logical analysis of the foundations of vector calculus." International Journal of Scientific Knowledge. Computing and Information Technology, vol. 3, pp. 25-30.

[48] Kalanov, T. Z., 2013. "The critical analysis of the Pythagorean theorem and of the problem of irrational numbers." Bulletin of Pure and Applied Sciences, vol. 32, pp. 1-12.

[49] Kalanov, T. Z., 2013. "The logical analysis of the Pythagorean theorem and of the problem of irrational numbers." Asian Journal of Mathematics and Physics, pp. 1-12. Available: http://scienceasia.asia

[50] Kalanov, T. Z., 2013. "The critical analysis of the Pythagorean theorem and of the problem of irrational numbers." Basic Research Journal of Education Research and Review, vol. 2, pp. 59-65. Available: http//www.basicresearchjournals.org

[51] Kalanov, T. Z., 2013. "Critical analysis of the mathematical formalism of theoretical physics. I. Foundations of differential and integral calculus." Bulletin of the Amer. Phys. Soc., vol. 58,

[52] Kalanov, T. Z., 2012. "On logical error underlying classical mechanics." Bulletin of the Amer. Phys. Soc., vol. 57,

[53] Kalanov, T. Z., 2012. "The correct analysis of theory of photon gas." Elixir, Nuclear \& Radiation Physics, pp. 10197-10205.

[54] Kalanov, T. Z., 2012. "The Boltzmann distribution: a logical error." Elixir, Adv. Pow., pp. 9935-9936.

[55] Kalanov, T. Z., 2012. "On rationalization of the foundations of differential calculus." Bulletin of Pure and Applied Sciences, vol. 31 E, pp. 1-7.

[56] Kalanov, T. Z., 2012. "Critical analysis of Bose-Einstein and Fermi-Dirac statistics." Elixir, Statistics, pp. 7657-7659.

[57] Kalanov, T. Z., 2012. "Critical analysis of the foundations of differential and integral calculus." International Journal of Science and Technology, vol. 1, pp. 80-84.

[58] Kalanov, T. Z., 2011. "Logical analysis of the foundations of differential and integral calculus." Bulletin of Pure and Applied Sciences, vol. 30 E, pp. 327-334.

[59] Kalanov, T. Z., 2011. "Logical analysis of the foundations of differential and integral calculus." Indian Journal of Science and Technology, vol. 4,

[60] Kalanov, T. Z., 2011. Critical analysis of the foundations of differential and integral calculus. MCMS, Ada Lovelace Publications, pp. 34-40.

[61] Kalanov, T. Z., 2011. "On the critical analysis of classical electrodynamics." Bulletin of the Amer. Phys. Soc., vol. 56,

[62] Kalanov, T. Z., 2011. "Analysis of the problem of relation between geometry and natural sciences." Prespacetime Journal, vol. 2, pp. 75-87.

[63] Kalanov, T. Z., 2010. The critical analysis of the foundations of theoretical physics. Crisis in theoretical physics, The problem of scientific truth. LAP Lambert Academic Publishing.

[64] Kalanov, T. Z., 2010. "The crisis in theoretical physics, The problem of scientific truth." Prespacetime Journal, vol. 1, pp. 824-842.

[65] Kalanov, T. Z., 2010. "The modern analysis of the problem of multisecting an angle." Prespacetime Journal, vol. 1, pp. 468-474.

[66] Kalanov, T. Z., 2010. "The theoretical model of God, Proof of the existence and the uniqueness of God." Scientific GOD Journal, vol. 2, pp. 85-97.

[67] Kalanov, T. Z., 2010. "On a new analysis of the foundations of classical mechanics. I. Dynamics." Bulletin of the Amer. Phys. Soc., vol. 55,

[68] Kalanov, T. Z., 2010. "On the Boltzmann distribution." Galilean Electrodynamics, vol. 21, p. 2.

[69] Kalanov, T. Z., 2009. "Theoretical model of God: proof of existence." Indian Journal of Science and Technology, vol. 2, pp. 80-88.

[70] Kalanov, T. Z., 2009. "On a new analysis of the problem of Planck constant." Bulletin of the Amer. Phys. Soc., vol. 54,

[71] Kalanov, T. Z., 2009. "The correct theory of photon gas." Indian Journal of Science and Technology, vol. 2, pp. 1-10.

[72] Kalanov, T. Z., 2009. "The correct theoretical analysis of the foundations of classical thermodynamics." Indian Journal of Science and Technology, vol. 2, pp. 12-17.

[73] Kalanov, T. Z., 2007. "The correct theoretical analysis of the foundations of classical thermodynamics." Bulletin of Pure and Applied Sciences, vol. 26D, pp. 109-118.

[74] Kalanov, T. Z., 2007. "Critical analysis of the special theory of relativity." Bulletin of Pure and Applied Sciences, vol. 26D, pp. 1-15.

[75] Kalanov, T. Z., 2007. "Theoretical model of God, The key to correct exploration of the Universe." Bulletin of the Amer. Phys. Soc., vol. 52, p. 121.

[76] Kalanov, T. Z., 2007. "On the hypothesis of control of the Universe." Bulletin of the Amer. Phys. Soc., vol. 52, p. 121. 
[77] Kalanov, T. Z., 2007. "On the correct analysis of the foundations of theoretical physics." Bulletin of the Amer. Phys. Soc., vol. 52, p. 120.

[78] Kalanov, T. Z., 2007. "On the correct analysis of the foundations of the special theory of relativity." Bulletin of the Amer. Phys. Soc., vol. 52, p. 120.

[79] Kalanov, T. Z., 2006. "On the correct analysis of Maxwell distribution." Bulletin of the Amer. Phys. Soc., vol. 51, pp. 61-62.

[80] Kalanov, T. Z., 2006. "Bose-Einstein statistics and Fermi-Dirac statistics, A logical error." Bulletin of the Amer. Phys. Soc., vol. 51, p. 61.

[81] Kalanov, T. Z., 2006. "Dirac's theory of physical vacuum, Continuation of Bose's logical errors." Bulletin of the Amer. Phys. Soc., vol. 51, p. 61.

[82] Kalanov, T. Z., 2006. "Bose's method, A logical error." Bulletin of the Amer. Phys. Soc., vol. 51 , p. 61.

[83] Kalanov, T. Z., 2006. "The second law of thermodynamics, Mathematical error." Bulletin of the Amer. Phys. Soc., vol. 51, p. 60.

[84] Kalanov, T. Z., 2006. "On the correct formulation of the first law of thermodynamics." Bulletin of the Amer. Phys. Soc., vol. 51, p. 60.

[85] Kalanov, T. Z., 2006. "On the hypothesis of Universe's, system block." Bulletin of the Amer. Phys. Soc., vol. 51, p. 61.

[86] Kalanov, T. Z., 2006. "The problem of the SETI, A methodological error in cosmology and astrophysics." Bulletin of the Amer. Phys. Soc., vol. 51, pp. 60-61.

[87] Kalanov, T. Z., 2006. "On a new theory of the black hole." Bulletin of the Amer. Phys. Soc., vol. 51 , p. 62.

[88] Kalanov, T. Z., 2006. "On a new approach to the solution of the problem of quantization of energy." Bulletin of the Amer. Phys. Soc., vol. 51, p. 62.

[89] Kalanov, T. Z., 2005. "On a new theory of physical vacuum." Bulletin of the Amer. Phys. Soc., vol. 50,

[90] Kalanov, T. Z., 2005. "On the correct theoretical analysis of the foundations of quantum mechanics." Bulletin of the Amer. Phys. Soc., vol. 50, p. 65.

[91] Kalanov, T. Z., 2004. "The correct theoretical analysis of the foundations of quantum mechanics." Journal of Ultra Scientists of Physical Sciences, International Journal of Physical Sciences, India, vol. 16, pp. 191198.

[92] Kalanov, T. Z., 2004. "On logical errors underlying the special theory of relativity." Journal of Theoretics, USA, vol. 6-1,

[93] Kalanov, T. Z., 2003. "The theory of relativity, An error of the transformation of coordinates." Bulletin of the Amer. Phys. Soc., vol. 48, p. 155.

[94] Kalanov, T. Z., 2003. "On the problem of knowledge of the universe." Bulletin of the Amer. Phys. Soc., vol. 48, pp. $154-155$.

[95] Kalanov, T. Z., 2003. "On the essence of space." Bulletin of the Amer. Phys. Soc, vol. 48, p. 154.

[96] Kalanov, T. Z., 2003. "On a new theory of the system of reference." Bulletin of the Amer. Phys. Soc., vol. 48, pp. 153-154.

[97] Kalanov, T. Z., 2003. "On the problem of the correspondence principle." Bulletin of the Amer. Phys. Soc., vol. 48 , p. 153.

[98] Kalanov, T. Z., 2002. "On a new basis of quantum theory." Bulletin of the Amer. Phys. Soc., vol. 47, p. 164.

[99] Kalanov, T. Z., 2002. "On the essence of time." Bulletin of the Amer. Phys. Soc, vol. 47, p. 164.

[100] Kalanov, T. Z., 2002. "On the main errors underlying statistical physics." Bulletin of the Amer. Phys. Soc, vol. 47, p. 164.

[101] Kalanov, T. Z., 2002. "On a solution of the problem of unitarization of the elementary principles of statistical physics and physical kinetics." Bulletin of the Amer. Phys. Soc, vol. 47, pp. 163-164.

[102] Kalanov, T. Z., 2001. "On logical errors lying in the base of special theory of relativity." Bulletin of the Amer. Phys. Soc., vol. 46, p. 99.

[103] Kalanov, T. Z., 2001. "Correct quantum-statistical description of ideal systems within the framework of master equation." In Proc. XXVth ICPIG, Nagoya Japan. p. 235.

[104] Kalanov, T. Z., 1999. "The most urgent problem of our time. Reports of the academy of sciences of the republic of Uzbekistan." p. 9.

[105] Kalanov, T. Z., 1999. "Kinematics of material point: Modern analysis. Reports of the academy of sciences of the republic of Uzbekistan." p. 9.

[106] Kalanov, T. Z., 1998. "On the theory of time. Reports of the academy of sciences of the republic of Uzbekistan." p. 24.

[107] Kalanov, T. Z., 1997. "On the theory of relative motion. Reports of the academy of sciences of the republic of Uzbekistan." p. 15.

[108] Kalanov, T. Z., 1996. "Proof of non-correctness of the lorentz transformation. Reports of the academy of sciences of the republic of Uzbekistan." p. 32.

[109] Kalanov, T. Z., 1995. "The correct theoretical analysis of the michelson-morley experiments. Reports of the academy of sciences of the republic of uzbekistan." p. 22.

[110] Kalanov, T. Z., 1993. "On a approach to the problem of substantiation and formulation of unitary basic principles of statistical physics and physical kinetic. Reports of the academy of sciences of the republic of Uzbekistan." 
[111] Kalanov, T. Z., 1992. "On the problem of substantiation and formulation of unitary basic principles of statistical physics and physical kinetics. Reports of the academy of sciences of the republic of uzbekistan." pp. 44-46.

[112] Kalanov, T. Z., 1992. "Physics without Boltzmann's, statistical entropy. Reports of the Academy of Sciences of the Republic of Uzbekistan." pp. 43-45.

[113] Kalanov, T. Z., 1992. "On the quantum-statistical theory of thermal radiation. Reports of the Academy of Sciences of the Republic of Uzbekistan." pp. 20-22.

[114] Kalanov, T. Z., 1991. "On the quantum-statistical theory of ideal monatomic gas, II. Reports of the Academy of Sciences of the Republic of Uzbekistan." pp. 23-25.

[115] Kalanov, T. Z., 1991. "On statistics of the systems with variable number of particles, II. Reports of the Academy of Sciences of the Republic of Uzbekistan." pp. 23-25.

[116] Kalanov, T. Z., 1991. "On statistics of the systems with variable number of particles, I. Reports of the Academy of Sciences of the Republic of Uzbekistan." pp. 26-28.

[117] Kalanov, T. Z., 1991. "On the quantum-statistical theory of ideal monatomic gas, I. Reports of the Academy of Sciences of the Republic of Uzbekistan." pp. 20-22.

[118] Kalanov, T. Z., 1991. "On the statistics of the electron gas. Reports of the Academy of Sciences of the USSR." vol. 316, p. 1386.

[119] Kalanov, T. Z., 1991. "On the statistics of the photon gas. Reports of the Academy of Sciences of the USSR." vol. 316, p. 100.

[120] Kalanov, T. Z., 1991. "Theoretical analysis of Einstein's relationship of detailed balance, II,Reports of the Academy of Sciences of the Republic of Uzbekistan." pp. 21-23.

[121] Kalanov, T. Z., 1990. "Theoretical analysis of Einstein's relationship of detailed balance, I .Reports of the Academy of Sciences of the Republic of Uzbekistan." pp. 22-24. 